\title{
An Alarming Situation of Suicide Patterns and Methods Involved in Pakistan
}

\author{
Adnan Liaqat ${ }^{1}$, Aisha Barlas ${ }^{1}$, Talal Barlas ${ }^{1}$, Muhammad Adnan ${ }^{2}$, Ishtiaq Anwar ${ }^{2}$ \\ ${ }^{1}$ Department of Medicine, Pakistan Ordinance Factory Hospital, Wah Cantt, Pakistan \\ ${ }^{2}$ Department of Ophthalmology, Edo Eye Hospital, Wah Cantt, Pakistan
}

Email address:

Adnan.liaqat873@yahoo.com (A. Liaqat), Aishab_93@hotmail.com (A. Barlas), talalbarlas@gmail.com (T. Barlas), dradnanmahsud@live.com (M. Adnan),sulehrionline99@hotmail.com (I. Anwar)

\section{To cite this article:}

Adnan Liaqat, Aisha Barlas, Talal Barlas, Muhammad Adnan, Ishtiaq Anwar. An Alarming Situation of Suicide Patterns and Methods Involved in Pakistan. American Journal of Psychiatry and Neuroscience. Vol. 5, No. 3, 2017, pp. 37-39. doi: 10.11648/j.ajpn.20170503.12

Received: April 5, 2017; Accepted: April 21, 2017; Published: May 31, 2017

\begin{abstract}
The act of deliberately killing an individual's own life is known as suicide. Suicide is an important social issue and major cause of mortality Worldwide. The data was obtained from Pakistan Ordinance Factories (POF) Hospital Wah Cantt, Tehsil Headquarter hospital Taxila and Hassan Abdal, Pakistan. Retrospective study design was used to review suicidal cases during 2013-2014 in three health centers of Pakistan. "A Guide for Manner of Death Classification" was used for assessing the suicidal identification criteria by National Association of Medical Examiners. Chi-square test was applied to see the association between qualitative variables. A total of 100 cases were retrieved. The mean age was found to be $27.12 \pm 10.11$ years. The peak age of suicidal attempts was seen in 20-30 years of age. The suicidal rate was found to be higher among males $29.99 \pm 12.73$ than females $23.03 \pm 7.669$. Study found out that suicide methods among all cases are $40 \%$ drug overdose, $20 \%$ wrist cutting, $10 \%$ hanging, $10 \%$ jumping from height, $10 \%$ chemical poising and $10 \%$ suicidal burns. The suicide rate is higher among Pakistani population but it was underestimated due to lack of reporting, cultural and religious reasons. Effective prevention requires a clear understanding of the size of the problem, its distribution in the population, and the major risk and protective factors at the levels of the individual, the family and the community.
\end{abstract}

Keywords: Suicide, Deliberate Killing, Hanging, Drug Overdose

\section{Introduction}

The act of deliberately killing an individual's own life is known as suicide [1]. Suicide is an important social issue and major cause of mortality Worldwide [2]. It was estimated that globally there are 1 million deaths per year following suicide and the number is projected to be 1.53 million in 2020 [3]. In last few decades, suicide emerged as an important social issue in Pakistan. The suicide rate in cities of Pakistan is at alarming level; 0.43/100,000 Peshawar and 2.86/100,000 in Rawalpindi [4]. In Sindh (Province of Pakistan), the rate of suicide is higher among males than females [5]. Moreover, males in age of 20 to 40 years are at high risk of attempting suicide $(7.06 / 100,000)$ than females [6]. In Pakistan, suicide emerged as a social stigma due to religious, social and political sensitivities. Pakistan is an Islamic state and by Islamic law suicide is considered as criminal offense punished by jail terms and financial penalty. In Islam, there are strong religious sanctions against suicide attempt [7]. Suicide attempts are considerably common among young males and females. The most common methods of suicide in Pakistan are; Hanging, firearms and use of insecticides. Most frequent reasons of suicide are interpersonal relationships issues and domestic problems while less frequent reason is mental illness. Suicides emerge as a challenging situation in Pakistan due to lack of resources, week political process and lack of access to mental health services [8]. There is no proper statistics available on suicide rate in Pakistan. Individuals avoid going in public sector hospital in Pakistan due to fear of harassment by police and social stigma. Ultimately, turning them towards private sector health system and leading towards underreporting of suicide statistics. Approximately, $34 \%$ of population is suffering from mental health issues in Pakistan while depression is projected to be leading cause of suicide among $90 \%$ of cases [9]. A limited 
data is available in Pakistan on patterns of suicides and different methods of suicides in Pakistan. The study will contribute knowledge during policy making regarding mental health in Pakistan. The study objective was to determine the suicide patterns and methods most frequently used for suicide attempt.

\section{Material and Methods}

The data was obtained from Pakistan Ordinance Factory (POF) Hospital Wah Cantt, Tehsil Headquarter hospital Taxila and Hassan Abdal, Pakistan. The hospital receives all the medico legal cases including suicidal cases mostly referred by police authorities. All the confirmed suicidal cases files signed by responsible authorities were retrieved for data review. Retrospective study design was used to review suicidal cases during 2013-2014 in three health centers of Pakistan. The data collection included demographic data, radiographic investigations, complete autopsy reporting and scene examination performed by forensic medical examiner. At the time of examination histopathological and toxicological screening process was utilized to find out cause of death. "A Guide for Manner of Death Classification" was used for assessing the suicidal identification criteria by National Association of Medical Examiners.

\subsection{Ethical Review}

Ethical Approval was taken from Ethical Review Board of POF Hospital, Wah Cantt, Pakistan. The ethical board was assured by researcher regarding confidentiality of all the cases.

\subsection{Data Analysis}

The data was analyzed using SPSS version 21 software. Data was analyzed using SPSS software version 20.0. Descriptive statistics (percentages, mean, SD) was used to describe the data. Results were reported in percentages, tables and charts for different variables according to nature of variable. Chi-square test was applied to see the association between qualitative variables.

\section{Results}

A total of 100 cases were retrieved. The mean age was found to be $27.12 \pm 10.11$ years. The peak age of suicidal attempts was seen in 20-30 years of age. The suicidal rate was found to be higher among males $29.99 \pm 12.73$ than females 23.03 \pm 7.669. Descriptive results as reported in Table 1 .

Table 1. Descriptive characteristics.

\begin{tabular}{lll}
\hline Characteristics & Frequency(N=100) & Percentage (\%) \\
\hline Gender & & \\
Males & 70 & $70 \%$ \\
Females & 30 & $30 \%$ \\
Age & & \\
$15-30$ & 60 & $60 \%$ \\
$31-45$ & 15 & $15 \%$ \\
$>45$ & 15 & $15 \%$ \\
\hline
\end{tabular}

\begin{tabular}{lll}
\hline Characteristics & Frequency(N=100) & Percentage (\%) \\
\hline Religion & & \\
Muslims & 90 & $90 \%$ \\
Hindu & 5 & $5 \%$ \\
Christen & 5 & $\% 5$ \\
\hline
\end{tabular}

The study found out that more than $1 / 3(37.1 \%)$ cases were students who attempted suicide. The suicide cases were found to be $20 \%$ among people who had private sectors jobs while $10.9 \%$ among Government sector employs. Suicidal rate was found to be $10.0 \%$ among housewives while in unemployed it was $9.8 \%$. A statistical significant difference Sex difference was reported $(\mathrm{P}=0.001)$.

The study found out that among all the cases $40 \%$ of deaths were due to drug overdose while $20 \%$ of deaths were due to wrist cutting.

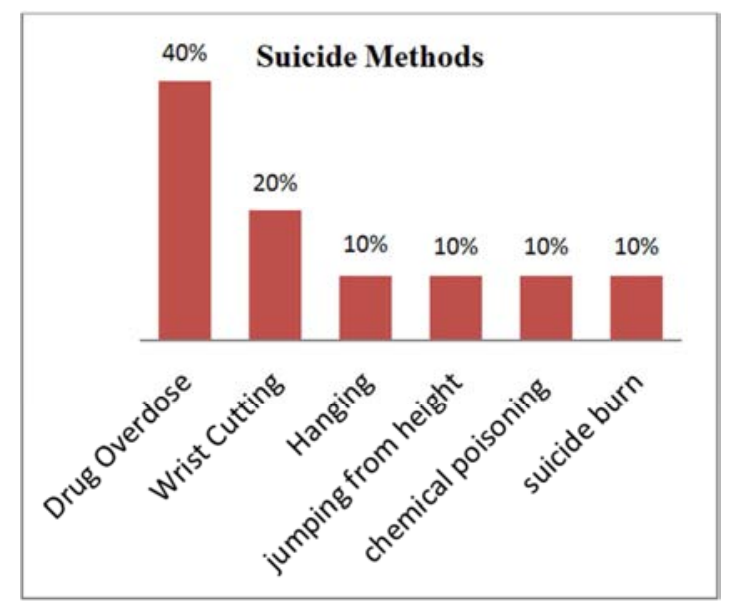

Figure 1. Suicide Methods Involved.

The distribution of suicidal outcome was found to be discharge 53.9\% among males and 80.6\% among females, leaving against medical advise $10.8 \%$ (males) and $14 \%$ (females), death $35.3 \%$ among males while $5.4 \%$ among females. The association was found to be statistically significant $\left(\chi^{2}=44.048, p=0.000\right)$. The study found out that mean duration of stay in hospital was $4.6 \pm 11.78$ days. While $1 / 3^{\text {rd }}$ cases were admitted to the hospital. The study dound out that $71 \%$ of suicidal cases $12.7 \%$ were left against medical advice from hospital while $16 \%$ were dead. The rate of death was $100 \%$ among hanging cases, $77.7 \%$ who jump from height, $66.7 \%$ in burn cases while $40 \%$ among wrist cases. Moreover the death cases were $11 \%$ in chemical poisoning and $1.5 \%$ in drug overdose cases. A significant association was found between suicidal marital cases and gender as shown in table 2 .

Table 2. Association between marital status and gender.

\begin{tabular}{llll}
\hline Marital status & Males & Females & Total \\
\hline Single & $40.2 \%$ & $60.8 \%$ & $53.6 \%$ \\
Married & $41.2 \%$ & $33.9 \%$ & $36.5 \%$ \\
Divorced & $9.8 \%$ & $4.4 \%$ & $6.3 \%$ \\
Widowed & $8.9 \%$ & $1.2 \%$ & $3.9 \%$ \\
\hline
\end{tabular}

$\left(\chi^{2}=19.71, \mathrm{p}=0.000\right)$ 


\section{Discussion}

Suicide is a leading cause of death in different countries and Pakistan is not an exception. Determination of death cause is an important phase of clinical investigation that leads towards suicidalor murdered results. The suicide reported confirmation is based on different interviews with deceased's family members, relatives, friends and psychologists opinions [10].

The present study included 100 suicidal cases from three health centers. The suicidal rate was found to be higher among males $29.99 \pm 12.73$ than females $23.03 \pm 7.669$. Hanna et al reported that two third of suicide cases were females while male to female ratio was 1:1.75 [11].

In present study mean age was found to be $27.12 \pm 10.11$ years. The peak age of suicidal attempts was seen in 20-30 years of age. While similar results are reported by another study with peak age of suicide between 20-29 years among both genders [12].

In present study the suicide rate was higher among working women and more significant among low age women. Paul et al. reported that among women, high psychiatric morbidity and suicidal behavior is strongly associated with early marriage, pressure to have arrange marriage, pressure of in laws to have a baby boy, joint family system and financial dependence upon husband [13].

In present study Suicidal rate was found to be $10.0 \%$ among housewives while in unemployed it was $9.8 \%$ and $46.9 \%$ among female students. A statistical significant difference Sex difference was reported $(\mathrm{P}=0.001)$. Okasha et al. reported that precipitating factors in Egypt were found to be different among males and females. Females reported bereavement, marital problems and romantic relationship problems as suicidal reason while financial issues and conflict at work place are major suicidal reasons [7].

The present study found out that suicide methods among all cases are $40 \%$ drug overdose, 20\% wrist cutting, 10\% hanging, $10 \%$ jumping from height, $10 \%$ chemical poising and $10 \%$ suicidal burns. Gross reported that the traditional methods of suicide are replaced by pesticide suicide and firearm suicide [14]. Most common method of suicide in Middle East is hanging [10]. While in a Scottish study, most common method was chemical poisoning [15]. In Saudia Arabia, most of suicides are due to firearms [16].

\section{Conclusion}

The suicide rate is higher among Pakistani population but it was underestimated due to lack of reporting, cultural and religious reasons. Effective prevention requires a clear understanding of the size of the problem, its distribution in the population, and the major risk and protective factors at the levels of the individual, the family and the community.

\section{References}

[1] Sinyor M, Tse R, Pirkis J. Global trends in suicide epidemiology. Curr Opin Psychiatry. 2017 Jan; 30(1):1-6.

[2] Park S, Ahn MH, Lee A, Hong JP. Associations between changes in the pattern of suicide methods and rates in Korea, the US, and Finland. Int J Ment Health Syst. 2014; 8:22.

[3] Kumar S, Verma AK, Bhattacharya S, Rathore S. Trends in rates and methods of suicide in India. Egypt J Forensic Sci. 2013 Sep; 3(3):75-80.

[4] Khan MM, Mahmud S, Karim MS, Zaman M, Prince M. Case-control study of suicide in Karachi, Pakistan. Br J Psychiatry. 2008 Nov 1; 193(5):402-5.

[5] Khan MM, Naqvi H, Thaver D, Prince M. Epidemiology of suicide in Pakistan: determining rates in six cities. Arch Suicide Res Off J Int Acad Suicide Res. 2008; 12(2):155-60.

[6] Hanna MM, A. El-Shereef EA, Griew AH. Study of pattern and outcome of suicidal methods used in Benghazi City Libya. Egypt J Forensic Sci. 2011 Sep; 1(3-4):124-32.

[7] Aggarwal N. Rethinking Suicide Bombing. Crisis. 2009 Mar $1 ; 30(2): 94-7$.

[8] Omar HA, Merrick J. The young and suicide. Int J Adolesc Med Health. 2013; 25(1):1-2.

[9] Al Ansari A, Hamadeh RR, Ali MK, El Offi A. Suicide in Bahrain in the last decade. Crisis. 2007; 28(1):11-5.

[10] Arun M, Palimar V, Kumar PGN, Menezes RG. Unusual methods of suicide: complexities in investigation. Med Sci Law. 2010 Jul; 50(3):149-53.

[11] Hanna MM, A. El-Shereef EA, Griew AH. Study of pattern and outcome of suicidal methods used in Benghazi City Libya. Egypt J Forensic Sci. 2011 Sep;1(3-4):124-32.

[12] Spicer RS, Miller TR. Suicide acts in 8 states: incidence and case fatality rates by demographics and method. Am J Public Health. 2000 Dec; 90(12):1885-91.

[13] Paul JP, Catania J, Pollack L, Moskowitz J, Canchola J, Mills $\mathrm{T}$, et al. Suicide Attempts Among Gay and Bisexual Men: Lifetime Prevalence and Antecedents. Am J Public Health. 2002 Aug; 92(8):1338-45.

[14] Gross JJ. Emotion Regulation in Adulthood: Timing Is Everything. Curr Dir Psychol Sci. 2001 Dec 1; 10(6):214-9.

[15] Hunt IM, Kapur N, Webb R, Robinson J, Burns J, Turnbull P, et al. Suicide in current psychiatric in-patients: a case-control study The National Confidential Inquiry into Suicide and Homicide. Psychol Med. 2007 Jun; 37(6):831-7.

[16] Al Madni OM, Kharoshah MAA, Zaki MK, Ghaleb SS. Hanging deaths in Dammam, Kingdom of Saudi Arabia. J Forensic Leg Med. 2010 Jul; 17(5):265-8. 